3. Appel LJ (2003), Lifestye Modification as a means to Prevent and Treat high blood pressure. J Am SocNephrol. 14: p. 99-102.

4. Francesco Fantin, et al. (2019), The Importance of Nutrition in Hypertension. Nutrients. 11: p. 25-42.

5. Katherine T. Mills, Andrei Stefanescu, Jiang He (2020), The global epidemiology of hypertension. Nature Reviews Nephrology. 16: p. 223-237.

6. Nurul Fatin Binti Buang, Nor Azlina A Rahman, Mainul Haque (2019), Knowledge, attitude and practice regarding hypertension among residents in a housing area in Selangor, Malaysia. Original Research. 92: p. 145-152.

7. Shibiru Tesema, et al. (2016), Knowledge, Attitude and Practice Regarding Lifestyle Modification of Hypertensive Patients at Jimma University Specialized Hospital, Ethiopia. Primary Health Care. 6(1): p. 1-2.

8. Udaya Ralapanawa, et al. (2020), Hypertension Knowledge, Attitude, and Practice in Adult Hypertensive Patients at a Tertiary Care Hospital in Sri Lanka. Research Article. 2020.

\title{
ĐẶC ĐIỂM DİCH TỄ CỦA NGộ ĐộC CẤP MộT Số MA TÚY MớI TẠI TRUNG TÂM CHỐNG Độ̉C BỆNH VIỆN BACH MAI
}

\section{TÓM TẮT}

Muc tiêu: Mô tả đă̆c điểm dich tễ của bênh nhân ngộ độc ma túy mới tại Trung tâm Chống độc Bệnh viện Bạch Mai. Đối tượng và phương pháp: Nghiên cứu mô tả 72bệnh nhần ngộ độc ma túy mới không phải nhóm opi điều trị tại Trung tâm Chống độc Bệnh viện Bạch Mai từ tháng 1/2017 đến 6/2019. Kết quả: Chủ yểu gặp ở Nam giới $(72,2 \%)$; tuổi trung bình là $30,57 \pm 9,3$ năm; người thất nghiệp $73,6 \%$; trình độ trung học phổ thông trở xuống $65,3 \%$; người độc thân $65,3 \%$; sống ở thành phố $59,7 \%$ và nông thổn $40,3 \%$. Một số loại ma túy mới thường gặp là Amphetamin (29,2\%), MET (22,2\%), MDMA (19,4\%), THC $(20,8 \%)$, Ketamin $(8,3 \%)$; chú yếu bệnh nhân dùng đường uống $(79,2 \%)$, đường hút, hít là $20,8 \%$. Bệnh nhân dùng ma túy do nghiện $(54,2 \%)$, được rủ $(26,4 \%)$, do thói quen $(19,4 \%)$; sử dụng tại vũ trường và địa điểm đông người $(58,3 \%)$, tại nhà $(41,7 \%)$; thường dùng vào ban đêm (72,2\%); dùng cùng người khác $(62,5 \%)$. Có $81,9 \%$ đã từng sử dụng ma túy trước đó và $18,1 \%$ ngô độc ở lần đâu sử dung. Kết luận: Đánh giá đặc điểm dịch tễ của ngộ độc ma túy cần thiết để xác định mô hình bệnh tật, giúp chẩn đoán và xử trí cấp cứu cho các bệnh nhân.

Tư khóa: ngộ độc ma túy

\section{SUMMARY \\ EPIDEMIOLOGY CHARACTERISTICS OF PATIENTSWITH DRUGS OF ABUSE POISONING AT POISON CONTROL CENTER BACHMAI HOSPITAL}

Objective: $\quad$ to describeepidemiology characteristics from patients with drugspoisoning. Subjects and Methods: Anobservational study

\footnotetext{
${ }^{1}$ Trung Tâm Chông Độc Bệnh viện Bạch Mai

${ }^{2}$ Trường Đại học Y Hà Nội

Chịu trách nhiệm chính: Đặng Thị Xuân

Email: xuandangthi@bachmai.edu.vn

Ngày nhận bài: 4.3.2021

Ngày phản biên khoa học: 23.4.2021

Ngày duyệt bài: 5.5.2021
}

\section{Đặng Thị Xuân ${ }^{1}$, Hà Trần Hưng ${ }^{1,2}$}

included 72 poisoned non-opium drugs patients treated at the Poison Control Center, Bach Mai Hospital from 1/2017 to 6/2019.Results:mostly accured in male with $72.2 \%$; the average age was $30.57 \pm 9.3$ years old; unemployed people $73.6 \%$; $65.3 \%$ below high school level; single people $65.3 \%$; living in city $59.7 \%$ and rural $40.3 \%$. Some common new drugs were Amphetamine (29.2\%), MET $(22.2 \%)$, MDMA (19.4\%), THC (20.8\%), Ketamine $(8.3 \%) ;$ Mainly used oral route $(79.2 \%)$, suction, inhalation was $20.8 \%$. Due to addiction (54.2\%), invited $(26.4 \%)$, habit $(19.4 \%)$; used at discos and crowded places $(58.3 \%)$, at home $(41.7 \%)$; usually used at night $(72.2 \%)$; shared with others $(62.5 \%)$ There were $81.9 \%$ people had used drugs before and $18.1 \%$ got poisoned at the first time use. Conclusion: Evaluating the epidemiological characteristics of drugs poisoning is necessary to identify disease patterns, essential for early diagnosis and management of patients.

Key words: drugs of abuse poisoning

\section{I. ĐĂT VẤN ĐỀ}

Ma túy là một vấn đề nhức nhối của xã hôi trong nhiều năm qua. Nghiện ma túy tại Việt Nam vẫn đang diển biến phức tạp với chiều hướng ngày càng gia tăng, số người nghiện đang ở cộng đồng chiếm tỉ lệ 64,5\% [1]. Trước đây, nhóm opi chiếm 3/4 chất gây nghiện thường được sử dụng. Thời gian gần đây các loại ma túy mới không phải nhóm opi được sử dụng ngày càng nhiều, như các loại ma túy tổng hợp, cần sa, ketamin, bóng cười. Cơ cấu người nghiện ma túy theo vùng miền cũng thay đổi đáng kể. Nếu như giữa những năm 90 của thế kỷ trước, nghiện ma túy chủ yếu phổ biến ở người dân tại các tỉnh miền núi phía Bắc thì từ giữa những năm 2000 đã tăng mạnh xuống vùng đồng bằng sông Hồng và khu vực miền Đông Nam Bộ. Cách thức sử dụng ma túy cũng có nhiều thay đổi, trước kia chủ yếu là chích hút thì hiện tại các ma túy mới có nhiều 
cách sử dụng như tiêm chích, hút hít, uống, ngậm dưới lưỡi hoặc trộn vào thực phẩm.

Trong những năm trước, Trung tâm Chống độc Bệnh viện Bạch Mai cấp cứu ngộ độc ma túy chủ yếu do quá hiều heroin, bệnh nhân vào vì suy hô hấp, ngừng thở, ngừng tim. Thời gian gần đây chủ yếu là ngộ độc các loại ma túy tổng hợp, cần sa, ketamin, cỏ Mỹ. Bệnh nhân vào viện vì loạn thần, ngáo, ảo giác. Các bệnh nhân nặng có thể gây tổn thương tim, suy tim, loạn nhịp tim, hôn mê, tiêu cơ vân, suy đa tạng, thậm chí tử vong. Diển biến và mức độ nặng phụ thuộc vào loại ma túy sử dụng, liều lượng, đường dùng và cách dùng. Việc xác định các yếu tố dịch tễ về đối tượng sử dụng và loại ma túy giúp định hướng cho mô hình bệnh tật, giúp chẩn đoán và xử trí cấp cứu bệnh nhân, vì vậy chúng tôi tiến hành nghiên cứu đề tài với mục tiêu "Nhận xét đặc điểm dịch tễ của ngộ độc cấp một số ma túy mới tại Trung tâm Chống độc Bệnh viện Bạch Mai".

\section{II. ĐỐI TƯợNG VÀ PHƯƠNG PHÁP NGHIÊN CỨU}

2.1. Đổi tượng nghiên cứu: Bệnh nhân ngộ độc ma túy khổng phải nhóm opi vào điều trị tại Trung tâm Chống độc từ 1/2017 đến 6/2019

* Tiêu chuẩn chọn bệnh nhân:Bệnh nhân có các tiêu chuẩn sau [2]

- Bênh sử sử dụng ma túy (ma túy đá, thuốc lắc, ketamin, cần sa, ...)

- Biểu hiện lâm sàng ngộ độc ma túy

- Xét nghiệm độc chất nước tiểu thây ma túy.

* Tiêu chuẩn loại trừ:

- Bệnh nhân sử dụng đồng thời ma túy nhóm opi (heroin, morphin, methadon)

- Ngộ độc đồng thời các chất khác: thuốc, hóa chất bảo vệ thực vật...

\subsection{Phương pháp nghiên cứu}

- Thiết kế nghiên cứu: Nghiên cứu mô tả, cõ mẫu thuân tiên.

- Tiến hành nghiên cứu: thu thập số liệu theo mẫu bệnh án nghiên cứu thống nhất

Các biến số nghiên cứu:

Tuổi, giới, nghề nghiệp, trình độ học vấn, tình trạng hôn nhân, địa dư

Thông tin về chất ma túy mới:

Loại ma túy bệnh nhân sử dụng

Đường dùng, cách dùng

Thông tin về việc sử dụng ma túy:

Thời gian sử dụng: lần đầu/ nhiều lần, thời điểm, tần suất dùng.

Tình trạng nghiện chất

Địa điểm sử dụng, sử dụng cùng ai

Thời gian sử dụng trước khi vào viện
2.3. Xử lý số liệu. Số liệu được xử lý theo phương pháp thống kê y học, sử dụng phần mềm SPSS 20.0. So sánh giá trị 2 trung bình bằng Student test, so sánh hai tỉ lệ bằng test $x^{2}$, mức ý nghĩa thống kê 95\%.

\section{KẾT QUẢ NGHIÊN CỨU}

3.1 Một số đặc điểm chung của bệnh nhân nghiên cứu

Trong thời gian nghiên cứu, có 72 bệnh nhân đủ tiêu chuẩn chọn. Kết quả cho thấy:

Bảng 1: Đặc điểm chung của bệnh nhân nghiên cứlu

\begin{tabular}{|c|c|c|}
\hline Đặc điểm & $\begin{array}{l}\text { Số bệnh } \\
\text { nhân (n) }\end{array}$ & $\begin{array}{c}\text { Tỉ lệ } \\
\%\end{array}$ \\
\hline \multicolumn{3}{|l|}{ Phân bố theo tuối } \\
\hline$<20$ tuối & 6 & 8,3 \\
\hline $20-29$ & 32 & 44,4 \\
\hline $30-39$ & 20 & 27,8 \\
\hline $40-49$ & 12 & 16,7 \\
\hline$\geq 50$ tuối & 2 & 2,8 \\
\hline Tuổi trung bình (năm) & $\begin{array}{c}30,57 \pm 9,3 \\
(15-55)\end{array}$ & \\
\hline \multicolumn{3}{|l|}{ Phân bố theo giới } \\
\hline Nam & 52 & 72,2 \\
\hline Nữ & 20 & 27,8 \\
\hline \multicolumn{3}{|l|}{ Nghề nghiệp } \\
\hline Cán bộ viền chức & 6 & 8,3 \\
\hline Cồng nhân & 3 & 4,2 \\
\hline Học sinh, sinh viên & 10 & 13,9 \\
\hline Thất nghiệp & 53 & 73,6 \\
\hline \multicolumn{3}{|l|}{ Trình độ học vấn } \\
\hline Cao đằng/Đại học & 11 & 15,3 \\
\hline Trung cấp/Nghề & 14 & 19,4 \\
\hline $\begin{array}{l}\text { Trung họ phố thông } \\
\text { trở xuống }\end{array}$ & 47 & 65,3 \\
\hline \multicolumn{3}{|l|}{ Tình trạng hôn nhân } \\
\hline Độc thân & 47 & 65,3 \\
\hline Đã kết hôn & 25 & 34,7 \\
\hline \multicolumn{3}{|l|}{ Nơi sống } \\
\hline Thành phố & 43 & 59,7 \\
\hline Nông thôn & 29 & 40,3 \\
\hline
\end{tabular}

Nhân xét: - Tuối trung bình của các bệnh nhân là 30,57 $\pm 9,3$ tuổi. Nhóm tuổi gặp nhiều nhất là

$20-29(44,4 \%$ ), sau đó đến nhóm tuổi 30 $39(27,8 \%)$.

- Giới: Chủ yếu gặp ở Nam giới (72,2\%), Nữ 27,8\%, tỉ lệ Nam/Nữ là 2,6:1

- Nghề nghiệp: đa số là người thất nghiệp $(73,6 \%)$, tiếp đến là học sinh/sinh viên $(13,9 \%)$, cán bộ viên chức $(8,3 \%)$, ít nhất là công nhân $4,2 \%$.Chủ yếu là trình độ trung học phổ thông trở xuống $(65,3 \%)$. Người độc thân $65,3 \%$; sống ở thành phố là $59,7 \%$. 


\subsection{Một số đặc điểm về sử dụng ma túycủa bệnh nhân}

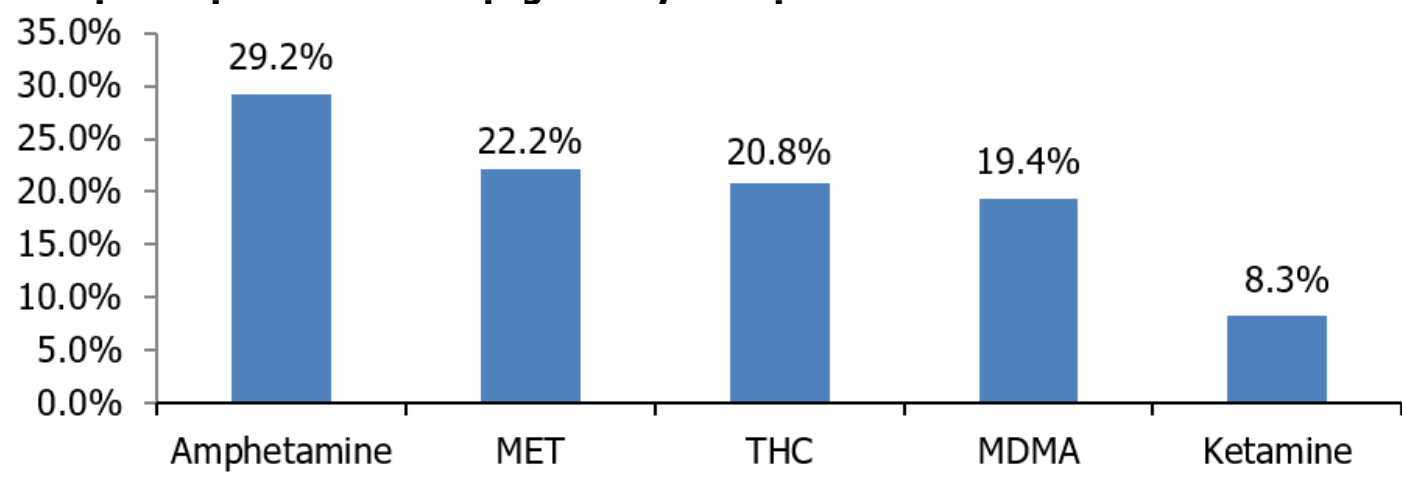

Biểu đồ 1: Các loai ma túy bênh nhân sử dung

Nhận xét: Loại ma túy sử dụng phổ biển nhất trong nghiên cứu là Amphetamin $21 \mathrm{BN}(29,2 \%)$; Metamphetamin (MET): 16 BN (22,2\%); Methylenedioxymethamphetamine (MDMA), thuốc lắc: 14 BN (19,4\%); Tetrahydrocannabinol (THC- có nhiều trong cần sa): 15 BN (20,8\%); ít nhất là Ketamin: 6 BN $(8,3 \%)$.

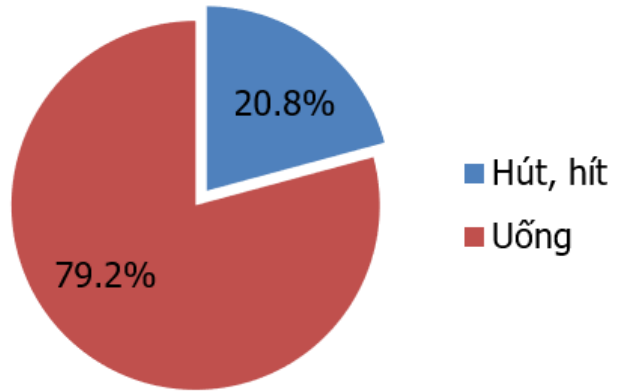

Biểu đồ 2: Đường dùng ma túy

Nhận xét: Bệnh nhân sử dụng ma túy đường uống là chủ yếu(79,2\%), đường hút, hít là $20,8 \%$.

Bảng 2: Đặc điểm vềsử dụng ma túy của bệnh nhân

\begin{tabular}{|c|c|c|}
\hline Đặc điểm & $\begin{array}{l}\text { Số bệnh } \\
\text { nhân(n) }\end{array}$ & $\begin{array}{c}\text { Tỉ lệ } \\
\%\end{array}$ \\
\hline \multicolumn{3}{|c|}{ Lý do sử dụng } \\
\hline Thói quen & 14 & 19,4 \\
\hline Người khác rủ & 19 & 26,4 \\
\hline Nghiện & 39 & 54,2 \\
\hline \multicolumn{3}{|c|}{ Địa điếm sử dụng } \\
\hline $\begin{array}{c}\text { Vũ trường, điếm đông } \\
\text { người khác }\end{array}$ & 42 & 58,3 \\
\hline Nhà & 30 & 41,7 \\
\hline \multicolumn{3}{|c|}{ Thời điếm sử dụng ma túy } \\
\hline Ngày & 20 & 27,8 \\
\hline Đêm & 52 & 72,2 \\
\hline \multicolumn{3}{|c|}{ Bối cảnh sử dụng ma túy } \\
\hline Một mình & 27 & 37,5 \\
\hline Cùng người khác & 45 & 62,5 \\
\hline \multicolumn{3}{|c|}{ Tiền sử sử dung ma túy } \\
\hline Từng sử dụng trước đó & 59 & 81,9 \\
\hline Lần đầu & 13 & 18,1 \\
\hline
\end{tabular}

Nhân xét: đặc điểm của lần vào viện này

- Hởn một nửa số đối tượng sử dụng ma túy lần này là do nghiện $(54,2 \%)$, do được rủ $(26,4 \%)$, và dùng theo thói quen $(19,4 \%)$.

- Đia điểm sử dụng phổ biến là vũ trường và địa điểm đông người $(58,3 \%)$, tại nhà $(41,7 \%)$

- Sử dụng vào ban đêm $(72,2 \%)$ cao hơn ban ngày $(27,8 \%)$.

- Dùng cùng người khác $(62,5 \%)$ cao hơn sử dụng một mình 37,5\%.

- Có $81,9 \%$ đã từng sử dụng ma túy trước đó và $18,1 \%$ ngộ độc ở lần đầu sử dụng.

\section{BÀN LUẬN}

4.1. Đặc điểm chung củabệnh nhân. Tuổi trung bình của đối tượng nghiên cứu là $30,57 \pm$ 9,3 tuổi, trẻ nhất mới 15 tuối và nhiều tuổi nhất là 55 tuổi. Phần lớn đối tượng nghiên cứu trong khoảng $20-40$ tuổi, trong đó tỉ lệ $20-29$ tuổi là $44,4 \%$ và $27,8 \%$ thuôc nhóm $30-39$ tuổi.Tác giả Rasmussen cũng thấy đô tuổi của người nghiên ma túy có xu hướng trẻ hóa, năm 2010 gần 70\% người nghiện ma túy ở độ tuổi dưới 30 trong khi năm 1995 chỉ khoảng 42\% [3]. Người trẻ tuổi là nhóm người mới lớn, ít kinh nghiệm sống, với đặc tính tâm lý chưa vững vàng, dề sa ngã.

Khi đánh giá về giới, chúng tôi thấy số bệnh nhân nam cao hơn nữ khá nhiều, tỉ lệ bệnh nhân nam là $72,2 \%$, nữ là $27,8 \%$, tỉ lệ $\mathrm{Nam} / \mathrm{Nữ}$ là 2,6:1.Trên thực tế ở nước ta, 95\% người nghiện ma túy là nam giới vì vậy tỉ lệ ngộ độc cấp ma túy cũng cao hơn. Đặc điểm về giới này cũng phổ biến trên thế giới. Tuy nhiên, bác cáo cũng cho thấy gần đây số lượng và chủng loại ma túy ngày càng đa dạng, sự tiếp cận với ma túy của người trẻ và giới nữ ngày càng tăng[3]. 
Trong nghiên cứu, chúng tôi thấy 73,6\% gặp ở người thất nghiệp. Nhiều người nghiện ma túy không có nghề nghiệp ổn định, chi tiêu chủ yếu từ nguồn hổ trợ của gia đình, thu nhập hợp pháp không đủ số tiền chi cho ma túy [3]. Điều đáng chú ý trong nghiên cứu của chúng tôi là tỉ lệ học sinh/ sinh viên chiếm 13,9\%; cán bộ viên chức chiếm $8,3 \%$ và $4,2 \%$ là công nhân. Tương tự, khi khảo sát về học vấn chúng tôi cũng thấy $65,3 \%$ số đối tượng nghiên cứu có trình độ trung học phổ thông trở xuống; tuy nhiên cũng có tới $15,3 \%$ có trình độ cao đắng/đại học và trung cấp/ nghề là 19,4\%. Những kết quả này cho thấy nghiện và ngộ độc chất gây nghiện không chỉ ở người có trình độ văn hóa thấp mà ở cả những người có trình độ cao.

Tỉ lệ đối tượng nghiên cứu là người độc thân chiếm 65,3\%. Mắc dù chưa xác định được cụ thể, nhưng có thể có mối liên quan giữa sử dụng chất gây nghiện với trẻ tuổi và độc thân.Hơn một nửa số đối tượng nghiên cứu sống ở thành phố $(59,7 \%)$, tỉ lệ đối tượng ở nông thôn là 40,3\%. Như vậy, các chất ma túy mới này không chî phổ biến ở thành phố, mà đã về nhiều vùng nông thôn.

*Một số đặc điểm về sử dụng ma túy của bệnh nhân. Các loại ma túy tổng hợp và ma túy mới đang ngày càng được sử dụng phổ biến, đặc biệt là trong lứa tuổi thanh, thiếu niên. Kết quả nghiên cứu cho thây loại ma túy sử dụng phổ biến nhất trong nghiên cứu là Amphetamine, chiếm $29,2 \%$. Tỉ lệ sử dụng MET $(22,2 \%)$, THC $(20,8 \%)$, MDMA $(19,4 \%)$ trong nghiên cứu khá tương đương nhau, khoảng $1 / 5$ trong nghiên cứu. Ketamin sử dụng ít nhất chiếm $8,3 \%$ số đối tượng. Những kết quả tương tự cũng đã được báo cáo tại Tây Ban Nha. Theo Gainza I, việc sử dụng chất gây nghiện bất hợp pháp những năm gần đây có sự thay đổi. Dường như tỉ lệ sử dụng heroin giảm đi, thay vào đó là sự tăng lên và xuất hiện mới của cocain, dẫn xuất Amphetamine như thuốc lắc (MDMA), thuốc lắc lỏng và môt tỉ lệ thấp ketamine[4].

Amphetamin lần đầu tiên được tổng hợp vào năm 1887 ở Đức bởi nhà hóa học người Rumani Lazăr Edeleanu, tác dụng kích thích của nó vẫn chưa được biết đến cho đến năm 1927, khi nó được tổng hợp bởi Gordon Alles [5]. Khi các đặc tính gây nghiện của thuốc được biết tới rộng rãi các chính phủ bắt đầu đặt những biện pháp kiểm soát chặt chẽ đối với việc bán amphetamin. Đầu những năm 1970 ở Hoa Kỳ, amphetamin trở thành một chất được kiểm soát theo cấp độ II theoĐạo luật về chất được kiểm soát.Ngày nay,
Amphetamin vẫn được tổng hợp bất hợp pháp trong các phòng thí nghiệm bí mật và được bán trên thị trường chợ đen, chủ yểu ở các nước châu Âu [6]. Amphetamin đặc biệt là MDMA, PMA đang ngày càng được sử dụng như chất gây nghiện phố biến. THC - Cần sa còn được gọi là marijuana/cannabis - cỏ,là một loại thuốc thần kinh từ cây Cannabis được sử dụng cho mục đích y tế hoặc giải trí. Chất kích thích thần kinh chính của cần sa là tetrahydrocannabinol (THC) [7]. MET là hoạt chất chủ yếu của các dạng chất gây nghiện như là ma túy đá hay còn gọi là hàng đá, chấm đá là tên gọi chỉ chung cho các loại ma túy tổng hợp.Loại ma túynày được giới sử dụng gọi là "đá" vì hình dạng bên ngoài trông giống đá - là tinh thể kết tinh thành những mảnh vụn li ti, gần giống với hạt mì chínhhoặc hạt muối và óng ánh giống đá. Ṅgoài dạng phổ biển trên, ma túy đá còn bán bất hợp pháp trên thị trường dưới các dạng cục, bột, viên nén. Đây là một loại ma tuý mới tồn tại dưới dạng thức tinh thể được dùng rất phổ biến hiện nay. Ketamin cũng là loại chất gây nghiện mới nổi, thường có trong các sản phẩm thuốc gây mê sử dụng trong y tế. Hiện nay, Ketamin được tìm thấy trong các sản phẩm như "Nước vui", "ma túy trà sữa"..

Các bệnh nhân trong nghiên cứu chủ yếu sử dụng ma túy đường uống $(79,2 \%)$, đường hút hít chỉ $20,8 \%$. Khác với ma túy heroin trước kia chủ yếu dùng theo đường hút, hít hoặc tiêm chích, các loại ma túy mới rất nhiều hình thức sử dụng: THC có thể sử dụng như hút thuốc, hít hơi, trộn vào trong thực phẩm ("bánh cân"), hoặc như một chất chiết xuất.Ma túy đá (MET) có thể được sử dụng theo cách như nuốt, hút, hít, uống hoặc tiểm. Loại ma túy này có thể hít trực tiếp qua đường mũi (sau khi nghiền nhỏ) hoặc cũng có thể gián tiếp thông qua một bình lọc đựng nước, hút bằng tẩu thuỷ tinh, tiêm chích (tỉ lệ rất nhỏ $<3 \%$ số người sử dụng). Chính vì sử dụng đường uống tiện hơn đường tiêm chích nên ngộ độc đường uống cũng gặp nhiều hơn.

Hơn một nửa số đối tượng sử dụng ma túy lần này là do nghiện $(54,2 \%)$, khoảng $1 / 4$ số người là sử dụng do được rủ $(26,4 \%)$ và dùng theo thói quen là $19,4 \%$ trong các bệnh nhân nghiên cứu.Đa số đối tượng nghiên cứu đã từng sử dụng ma túy trước đó $(81,9 \%)$. Tỉ lệ bị ngộ độc ở lần đầu sử dụng trong nghiên cứu là $18,1 \%$. Rõ ràng, ngộ độc chất gây nghiện không chỉ xảy ra với người lần đầu sử dụng mà có thể ở cả người quen sử dụng, thậm chí là nghiện ma túy.Địa điểm sử dụng phổ biến là tại nhà $(41,7 \%)$ hoặc các địa điểm khác $(40,3 \%)$. Có 
$18,1 \%$ số đối tượng sử dụng ma túy tại vũ trường trước khi bị ngộ độc.Trước khi ngộ độc lần này, phần lớn đối tượng sử dụng ma túy vào ban đêm, chiếm $72,2 \%$ và hơn một nửa số đối tượng sử dụng ma túy cùng người khác $(62,5 \%)$. Có thể thấy rằng, ngộ độc ma túy có thể xảy ra ở bất cứ thời gian, địa điểm nào, dù sử sử dụng một mình hay cùng người khác. Nhiều người sử dụng tới khi kiệt sức và sử dụng liêu sau ngay khi liều trước đó hết hoặc giảm tác dụng bất kể thời gian.

\section{KẾT LUÂN}

Đặc điểm về dịch tễ của các bệnh nhân ngộ độc ma túy mới, không phải nhóm opi:

Chủ yếu gặp ở Nam giới $(72,2 \%)$, Nữ giới 27,8\%,tỉ lệ Nam/Nữ 2,6:1; Tuổi trung bình là $30,57 \pm 9,3$ tuổi; người thất nghiệp 73,6\%; trình độ trung học phố thông trở xuống $(65,3 \%)$; người độc thân $65,3 \%$; sổng ở thành phố $59,7 \%$ và nông thôn 40,3\%.

Một số loại ma túy mới thường gặp là Amphetamin $(29,2 \%)$, MET $(22,2 \%)$, MDMA $(19,4 \%)$, THC $(20,8 \%)$, Ketamin $(8,3 \%)$; chủ yêuu bệnh nhân dùng đường uống $(79,2 \%)$, đường hút, hít là 20,8\%.

Bệnh nhân dùng ma túy do nghiện $(54,2 \%)$, được rủ $(26,4 \%)$, do thói quen $(19,4 \%)$; sử dụng tại vũ trường và địa điểm đông người $(58,3 \%)$, tại nhà $(41,7 \%)$; thường dùng vào ban đêm $(72,2 \%)$; dùng cùng người khác $(62,5 \%)$. Có $81,9 \%$ đã từng sử dụng ma túy trước đó và 18,1\% ngộ độc ở lần đầu sử dụng.

\section{TÀI LIỆU THAM KHẢO}

1. Nguyễn Thanh Long và và công sự (2010). "Hành vi nguy cơ lây nhiếm và tỉ lệ nhiếm HIV trong nhóm nghiên chích ma túy tại khu vực nông thôn miền núi tỉnh Bắc Giang, năm 2010". Tạp chí Y học thực hành, số 742-743: 197-200

2. Nguyễn Thị Du (2004). Định hướng chung chẩn đoán và xứ trí ngộ độc cấp, Tư vấn chẩn đoán và xử trí nhanh ngộ độc cấp. Nhà xuất bản $Y$ học Hà Nội. 2004; 9-22.

3. Rasmussen N. (2011)."Medical science and the military: the Allies' use of amphetamine during World War II". J Interdiscip Hist, 42(2): 205-33.

4. Gainza I., Nogue $S$., Martinez Velasco $C_{\text {., }}$ et al (2003), "Drug poisoning", An Sist Sanit Navar, 26 (1): 99-128.

5. David Sulzer, Mark S. Sonders, Nathan W. Poulsen et al (2005). "Mechanisms of neurotransmitter release by amphetamines: A review". Progress in Neurobiology, 75(6): 406-433.

6. Wilson A (2008), "Mixing the Medicine: The unintended consequence of amphetamine control on the Northern Soul Scene", Internet Journal of Criminology.

7. George Sam Wang (2020), "Cannabis (marijuana): Acute intoxication", Uptodate 2020.

\title{
TÌNH HÌNH TRẦM CẢM VÀ MộT Số YẾU TỐ LIÊN QUAN Ở NGƯỜ'I DÂN QUÂAN NINH KIỀU, THÀNH PHỐ CẦN THO'
}

\author{
Nguyễn Tấn Đạt*, Hồ Thế Nhân*, Dương Phúc Lam*, \\ Nguyễn Minh Phương*, Nguyễn Trung Kiên*
}

\section{TÓM TẮT}

Đặt vấn đê: Trâm cảm làm gia tăng nhu câu chăm sóc sức khỏe, giảm chất lượng cuộc sống và có nguy cơ tự tử cao. Mục tiêu nghiên cứu: Xác định tỷ lệ trầm cảm và một yếu tố liên quan đến trầm cảm ở người trưởng thành tại thành phố Cần Thơ. Đối tượng và phương pháp nghiên cứu: Nghiên cứu mô tả cắt ngang có phân tích trên 449 người từ 18-60 tuổi tại quận Ninh Kiều, thành phố Cân Thơ từ tháng 9/2016 đến 6/2017. Trầm cảm được đo lường dựa trên thang điểm PHQ-9. Tổng điểm 9 mục dao động từ 0 đến 27 điểm. Tổng điểm $5,10,15,20$ tương ứng với các điểm cắt mức độ trầm cảm nhẹ, vừa, nặng, rất

*Trường Đại học Y Dước Cần Tho

Chịu trách nhiệm chính: Nguyễn Tấn Đạt

Email: ntdat@ctump.edu.vn

Ngày nhận bài: 2.3.2021

Ngày phản biên khoa hoc: 27.4.2021

Ngày duyệt bài: 10.5.2021 năng. Kết quả: 16\% đối tượng tham gia nghiên cứu mắc trầm cảm, với điểm cắt từ 5 trở lên. Có $76,4 \%$ đối tượng trầm cảm nhẹ; $18,1 \%$ vừa; $4,1 \%$ nặng vừa; $1,4 \%$ nặng. Bệnh mạn tính $(O R=2,79 ; p=0,005)$, tính cách trầm tính/dễ xúc đông $(\mathrm{OR}=3,12 ; \mathrm{p}=0,002)$, thất bại trong công việc/học tập ( $O R=4,40 ; p<0,001)$; tiền sứ gia đình có người bi tâm thần $(\mathrm{OR}=8,93$; $\mathrm{p}=0,029)$, gia đình không hạnh phúc $(\mathrm{OR}=5,61$; $\mathrm{p}=0,002)$, người thân mất/bểnh năng $(\mathrm{OR}=2,75$; $\mathrm{p}=0,004)$ được tìm thấy có ý nghĩa thổng kê liên quan đến trầm cảm. Kết luận: Nghiên cứu này cung cấp một tín hiệu báo động cho các chuyên gia y tế và các nhà hoach định chính sách y tế tai thành phố Cần Thơ sự cần thiết việc phát hiện tốt hởn về bệnh trầm cảm và các yếu tố liên quan ở người trưởng thành.

Tư khóa: trầm cảm, yếu tố liên quan, Ninh Kiều, Cần Thơ.
SUMMARY
DEPRESSION AND ITS ASSOCIATED FACTORS AMONG ADULTS IN NINH KIEU 